\title{
Vitamin B12 Status in Type 2 Diabetes Mellitus Patients on Metformin therapy: A Teaching Hospital Based Study
}

\author{
Kamal Rajesh Jampana', Atchuta Chytanya Paka² \\ ${ }^{1}$ Associate Professor, Department of General Medicine, Nimra Institute of Medical Sciences, Nimra Nagar, Ibrahimpatnam, Jupudi, Vijayawada, Andhra Pradesh- \\ $521456,{ }^{2}$ Assistant Professor, Department of General Medicine, NRI Academy of Sciences, Mangalagiri Road, Chinakakani, Guntur, Andhra Pradesh-522503.
}

\section{Abstract}

Background: Diabetes is fast gaining the status of a potential epidemic in India, with more than 62 million diabetic individuals currently diagnosed with the disease. Subjects and Methods: 50, Type-2 diabetic patients on metformin therapy, with age ranging from 30 to 65 years and 50 healthy controls, were recruited from the General Medicine Department of Nimra Institute of Medical Sciences, according to inclusion and exclusion criteria. Results: In this study, the level of FBS, HbA1c, Fasting insulin, Homocysteine, C peptide, and Methyl Malonic acid were significantly increased ( $\mathrm{p}<0.01$ ), while Vitamin B12 levels were significantly decreased $(\mathrm{p}<0.01)$ in the study group, as compared to controls. It was observed that the mean level of vitamin B12 markers, homocysteine and methylmalonic acid were significantly higher and low level of vitamin B12 was found in patients who were on metformin therapy. Reports have shown that metformin use has a significant impact on the concentration of vitamin B12 in patients with T2DM.Conclusion: Metformin, which is the first line oral hypoglycemic agent as recommended by ADA, is significantly associated with decrease in vitamin B12 levels. There is moderate correlation between the markers of B12 status and levels of fasting blood sugar as well as HbA1C. There is a significant correlation between insulin and C-peptide with the markers of vitamin B12 status.

Keywords: Type 2 DM, Vitamin B12, Fasting insulin, Homocysteine and Methyl Malonic Acid.

Corresponding Author: Dr. Atchuta Chytanya Paka, Assistant Professor, Department of General Medicine, NRI Academy of Sciences, Mangalagiri Road, Chinakakani, Guntur, Andhra Pradesh-522503.

Received: January 2019

Revised: February 2019

Accepted: March 2019

\section{Introduction}

Type 2 Diabetes mellitus is a heterogeneous group of disorders, characterized by variable degree of insulin resistance, impaired insulin secretion and increased glucose production. Diabetes is fast, gaining the status of a potential epidemic in India, with more than 62 million diabetic individuals currently diagnosed with the disease. ${ }^{[1,2]}$ With an ever-increasing incidence of type 2 diabetes in the Indian population, continual assessment must be made to ensure the ongoing evaluation of treatment options and to ensure that patient care is not compromised. Metformin is considered a cornerstone in the treatment of diabetes and is the most frequently prescribed first line therapy for individuals with type 2 diabetes. Every year Metformin caters to the need of more than 150 million people, the reason being its therapeutic efficacy and affordable price. ${ }^{[3]}$ The mechanism of action of Metformin in improving hyperglycemia involves improving the signaling of insulin, together with suppressing hepatic gluconeogenesis. In addition, it is one of a few anti-hyperglycaemic agents associated with improvements in cardiovascular morbidity and mortality, which is a major cause of death in patients with type 2 diabetes. Metformin does, however, induce vitamin B-12 malabsorption, which may increase the risk of developing vitamin B-12 deficiency-a clinically important and treatable condition. In addition, metformin treatment has been reported to be associated with decreased folate concentration, although the mechanism of this effect has not been elucidated. Finally, decrease in both folate and vitamin B-12 concentrations might, in turn, result in an increase in homocysteine concentration, an independent risk factor for cardiovascular disease, especially among individuals with type 2 diabetes. ${ }^{[4]}$ Vitamin B12, also called cobalamin, is a water-soluble vitamin involved in the optimal functioning of the hemopoetic, neuro-cognitive and vascular systems. It is involved in DNA synthesis, fatty acid metabolism and energy production. ${ }^{[5]}$ Vitamin B12 plays a vital role in DNA and cellular metabolism by serving as an essential co-factor in methylation process. Hence a deficiency leads to DNA disruption and derangement of cellular metabolism. This might lead to serious clinical consequences. Vitamin B12 is intracellularly converted to two active co-enzymes, adenosylcobalamin in mitochondria and methylcobalamin in the cytoplasm. They are necessary for the homeostasis of Methyl malonic acid (MMA) and Homocysteine (HC). Methylmalonic acid is converted into succinyl-CoA, of 
which, vitamin $\mathrm{B} 12$ is a cofactor for the reaction. Homocysteine is biosynthesized from methionine then resynthesized into methionine or converted into amino acid cysteine. ${ }^{[6]}$ Markers which are increased early in vitamin B12 deficiency include serum Methyl malonic acid and Homocysteine. Measurement of serum Methyl malonic acid and Homocysteine levels are more sensitive methods of screening for vitamin B12 deficiency. ${ }^{[7]}$ High levels of Methyl malonic acid and $\mathrm{HC}$ have been identified as better indicators of B-12 deficiency than the actual serum B-12 level itself. A deficiency of vitamin B-12 at the tissue level elevates the levels of both Methyl malonic acid and Homocysteine, even when serum vitamin B-12 concentrations are within the reference values. This study was therefore, carried out to evaluate the serum levels of Vitamin B12 Status in Type 2 Diabetes Mellitus Patients on Metformin therapy.

\section{Subjects and Methods}

This study was conducted in the Department of Medicine, Nimra Institute of Medical Sciences in collaboration with the Department of Biochemistry, during the period of sixteen months i.e., from September 2016 to December 2017. Randomly selected 70 subjects, according to exclusion \& inclusion criteria, with age in between 30-65 years, were categorized in two groups:

Group: A - 50 patients with type 2 diabetic patients on metformin therapy.

Group: B- 50 non- diabetic subjects as healthy controls

\section{Biochemical investigation:}

After the overnight fast of about 10-12 hours, $5 \mathrm{ml}$ of venous blood was collected from each participant. The samples were allowed to retract and then spun at $3000 \mathrm{rpm}$ for 12 minutes to obtain serum samples which were kept at $20^{\circ} \mathrm{c}$ until analysed for vitamin B12 level. Fasting blood glucose was estimated by GOD POD and HbA1C was estimated by cation exchange resin methods. Samples were analyzed for the following study variables - vitamin B12, homocysteine, methyl malonic acid, plasma insulin and CPeptide using Fully automated Cobas e 411.

\section{Statistical analysis:}

All values were expressed as Mean \pm SD. We used student ttest and pearson's correlation coefficient to find the statistical significance. A p-value $<0.05$ was to be considered statistically significant.

\section{Results\&Discussion}

This study was conducted in the Department of Medicine, Nimra Institute of Medical Sciences in collaboration with the Department of Biochemistry. [Table-I] shows the demographic characteristics of the study and control group. A total of 50 Type 2 Diabetic patients as cases and 50 Healthy subjects as controls were included in this study.
The mean age (Mean \pm SD) of cases and controls were 47.59 \pm 7.42 and $43.62 \pm 5.42$ years respectively. Similarly, the mean BMI, Systolic BP and Diastolic BP of both the cases and controls were $(27.24 \pm 4.38 \& 24.14 \pm 3.42)$; $(126.86 \pm$ $16.15 \& 108.02 \pm 2.60)$ and $(75.23 \pm 9.68 \& 74.21 \pm 3.72)$ respectively.

Table 1: Demographic profile of cases and controls

\begin{tabular}{|c|c|c|c|}
\hline \multicolumn{2}{|c|}{ Variables } & $\begin{array}{l}\text { Study Group } \\
(\text { Mean } \pm \text { SD) }\end{array}$ & $\begin{array}{l}\text { Control Group } \\
(\text { Mean } \pm \text { SD) }\end{array}$ \\
\hline \multicolumn{2}{|c|}{ Age in years } & $47.59 \pm 7.42$ & $43.62 \pm 5.42 *$ \\
\hline \multirow{2}{*}{ Gender } & Male & $23(46 \%)$ & $21(42 \%)$ \\
\hline & Female & $27(54 \%)$ & $29(58 \%)$ \\
\hline \multicolumn{2}{|c|}{ Height (m) } & $1.64 \pm 0.09$ & $1.61 \pm 0.07 *$ \\
\hline \multicolumn{2}{|c|}{ Body weight (kg) } & $72.2 \pm 11.56$ & $68.34 \pm 9.71 *$ \\
\hline \multicolumn{2}{|c|}{ BMI $(\mathrm{kg} / \mathrm{m} 2)$} & $27.24 \pm 4.38$ & $24.14 \pm 3.42 *$ \\
\hline \multicolumn{2}{|c|}{ Systolic BP ( mmHg) } & $126.86 \pm 16.15$ & $108.02 \pm 2.60$ \\
\hline \multicolumn{2}{|c|}{ Diastolic BP (mmHg) } & $75.23 \pm 9.68$ & $74.21 \pm 3.72$ \\
\hline
\end{tabular}

(Statistically Significant at p value $<0.05) * N S$ : Statistically not Significant

Table 2: Comparison of glycemic and vitamin b12 status of cases and controls

\begin{tabular}{|l|l|l|}
\hline $\begin{array}{l}\text { Biochemical } \\
\text { markers }\end{array}$ & $\begin{array}{l}\text { Study Group } \\
(\text { Mean } \pm \text { SD })\end{array}$ & $\begin{array}{l}\text { Control Group } \\
(\text { Mean } \pm \text { SD })\end{array}$ \\
\hline Fasting glucose & $154.21 \pm 60.56$ & $76.3 \pm 15.05$ \\
\hline HbA1c \% & $8.12 \pm 3.14$ & $4.31 \pm 1.02$ \\
\hline Fasting insulin & $8.36 \pm 2.6$ & $6.01 \pm 2.04$ \\
\hline Homocysteine & $14.2 \pm 4.18$ & $7.56 \pm 2.56$ \\
\hline C-peptide & $4.25 \pm 1.04$ & $2.6 \pm 0.62$ \\
\hline Methyl Malonic acid & $155.41 \pm 78.16$ & $122 \pm 84.23$ \\
\hline Vitamin B12 & $218.45 \pm 85.34$ & $370.04 \pm 91.56$ \\
\hline
\end{tabular}

(Statistically Significant at $\mathrm{p}$ value $<0.05) *$ NS: Statistically not Significant

[Table 2] shows the mean levels of Fasting glucose, GlycatedHaemoglobin, Fasting insulin, Homocysteine,

C peptide, Methyl Malonic acid and Vitamin B12 levels in both the study and control groups. The mean \pm sd values in the study group are as follows; $154.21 \pm 60.56,8.12 \pm 3.14$, $8.36 \pm 2.6, \quad 14.2 \pm 4.18, \quad 4.25 \pm 1.04, \quad 155.41 \pm 78.16 \quad \&$ $218.45 \pm 85.34$. Similarly, the mean \pm sd values in the control group are as follows; $76.3 \pm 15.05,4.31 \pm 1.02,6.01 \pm 2.04$, $7.56 \pm 2.56,2.6 \pm 0.62,122 \pm 84.23 \& 370.04 \pm 91.56$. In this study, the level of FBS, HbA1c, Fasting insulin, Homocysteine, $\mathrm{C}$ peptide, and Methyl Malonic acid were significantly increased ( $p<0.01)$ while Vitamin B12 level was significantly decreased $(\mathrm{p}<0.01)$ as compared to controls. It was observed that the mean levels of vitamin B12 markers,homocysteine and methylmalonicacid were significantly higher and low level of vitamin B12 was found in patients who were on metformin therapy. Reports have shown that metformin use has a significant impact on the concentration of vitamin B12 in patients with T2DM. ${ }^{[8-10]}$

It was observed the prevalence of decreased serum vitamin B12 status in metformin treated patients in the present study was lower than those in the Green et al study. ${ }^{[11]}$ This comparison must be interpreted with caution as there are other factors that may affect the serum Vitamin B12 of these patients which were not addressed in this study (diet, drug interactions etc.). Furthermore as the patients recruited into the Green et al study were non-institutionalized there may have been a level of malnutrition in regards to nutritional intake as has been observed in such populations 
(McElnay et al). ${ }^{[12]}$ The mechanism of metformin inhibition of absorption is not fully understood. The current theory of inhibition is based on interference with intrinsic factor binding in the gut. It would be assumed that an increase in concentration of the inhibiting substance (metformin) would result in an increase in inhibition of said absorption. As metformin is excreted unchanged in urine with an elimination half-life of approximately 5 hours (Graham et al) it would be logical for the relationship between metformin and vitamin B12 malabsorption to be somewhat linear. ${ }^{[13]}$

Table 3: Correlation of glycemic status with vitamin B12deficiency markers

\begin{tabular}{|l|c|c|c|c|}
\hline Parameters & $\begin{array}{c}\text { Homocysteine } \\
(\mathbf{r})\end{array}$ & $\begin{array}{c}\text { p- } \\
\text { value }\end{array}$ & $\begin{array}{c}\text { Methylmalonic } \\
\text { Acid (r) }\end{array}$ & $\begin{array}{c}\text { p- } \\
\text { value }\end{array}$ \\
\hline FBS & +0.42 & 0.002 & +0.33 & 0.01 \\
\hline HbA1c & +0.35 & 0.01 & +0.34 & 0.01 \\
\hline Insulin & +0.40 & 0.004 & +0.42 & 0.002 \\
\hline C-peptide & +0.43 & 0.001 & +0.47 & 0.000 \\
\hline
\end{tabular}

(Statistically Significant at $\mathrm{p}$ value $<0.05$ )

We have correlated the markers of glycemic status with the markers of Vitamin B12 deficiency,Homocysteine and Methylmalonic acid. Table 3 showed the positive correlation between these two markers. Total serum vitamin B12 is a relatively insensitive and unspecific biomarker of deficiency that does not reflect recent variations in cobalamin status. Holotranscobalamin, the metabolically active portion of vitamin B12, is the earliest laboratory parameter that becomes decreased in case of a vitamin B12 negative balance.

Concentration of methylmalonic acid is a functional vitamin B12 marker that will increase when the vitamin B12 stores are depleted. Isolated lowering of holotranscobalamin shows vitamin B12 depletion (negative balance), while lowered holotranscobalamin plus elevated methylmalonic acid (and homocysteine) indicates a metabolically manifested vitamin B12 deficiency, although there still may be no clinical symptoms. ${ }^{[14]}$ The concentration of total homocysteine in serum and plasma is elevated in both folate and cobalamin deficiencies, whereas methylmalonic acid in serum, plasma, or urine is a specific marker of cobalamin function. The combined measurement of both metabolites is useful for the diagnosis and follow-up of these deficiency states. In addition, total homocysteine is elevated under various pathologic states (eg: renal failure), and hyperhomocysteinemia is associated with an increased risk of cardiovascular disease, cognitive dysfunction, and adverse pregnancy outcomes. ${ }^{[15]}$ The relationship between insulin and homocysteine is controversial. However, handful of studies have found strong associations between insulin and homocysteine. One study in humans found that B-12 and Folate therapy resulted in a number of improved parameters among patients with metabolic syndrome. ${ }^{[16]}$ Glycated hemoglobin(HbA1c) is an independent risk factor for type 2 diabetes. Subjects with high-normal levels of HbA1c deserve particular attention because they have a strong risk of developing diabetes. ${ }^{[17]}$ In this study the correlation between fasting blood glucose and HbA1c was analyzed with the markers of vitamin B12 and no correlation existed between them. In the transition from normal glucose tolerance to type 2 diabetes mellitus, the role of $\beta$-cell dysfunction and peripheral insulin resistance is well established. In this study there is a significant correlation between insulin and C-peptide with the markers of vitamin B12 status.

\section{Conclusion}

In conclusion, there is moderate correlation between the markers of B12 status and levels of fasting blood sugar as well as $\mathrm{HbA} 1 \mathrm{C}$. There is a significant correlation between insulin and C-peptide with the markers of vitamin B12 status. This present study concludes that metformin, which is the first line oral hypoglycemic agent as recommended by ADA, is significantly associated with decrease in vitamin B12. So we recommend that vitamin B12 should be measured prior to initiation of metformin therapy and later, annually, in patients of type 2 diabetes mellitus who are on metformin therapy. Also this study revealed that the majority of the patients are being investigated for Vitamin B12 deficiency, which is a very positive sign for the health care system. So we recommend routine screening for basal vitamin B12 level for all patients with T2DM at the initiation of metformin therapy with subsequent annual follow up of the level.

\section{References}

1. Joshi SR, Parikh RM. India - diabetes capital of the world: now heading towards hypertension. J Assoc Physicians India. 2007;55:323-4.

2. Kumar A, Goel MK, Jain RB, Khanna P, Chaudhary V. India towards diabetes control: Key issues. Australas Med J. 2013;6(10):524-31.

3. An $\mathrm{H}$ and He L. Current understanding of metformin effect on the control of hyperglycemia in diabetes. J Endocrinol 2016; 228: R97R106.

4. Jolien de Jager, Coen D A Stehouwer et al. Long term treatment with metformin in patients with type 2 diabetes and risk of vitamin B-12 deficiency: randomized placebo controlled trial, BMJ 2010;340:c2181.

5. Yamada K. Cobalt: It's Role in Health and Disease. In Astrid Sigel, Helmut Sigel and Roland K. O. Sigel. Interrelations between Essential Metal Ions and Human Diseases. Metal Ions in Life Sciences 2013; Springer. 295-320.

6. Hunt A, Harrington D and Robinson S. Vitamin B12 deficiency. BMJ 2014; 349: g5226-g5226.

7. Oh R and Brown DL. Vitamin B12 deficiency. Am Fam Physician 2003; 67: 979-986.

8. Adams JF, Clark JS, Ireland JT et al. Malabsorption of vitamin B12 and intrinsic factor secretion during biguanide therapy. Diabetologia 1983; 24: 16-18.

9. Pongchaidecha M, Srikusalanukul V, Chattananon A, Tanjariyaporn S. Effect of metformin on plasma homocysteine, vitamin B12 and folic acid: a cross-sectional study in patients with type 2 diabetes mellitus. J Med Assoc Thai 2004; 87: 780-787.

10. Raheel I, Sultan MK, Adnan Q et al. Prevalence of Vitamin B12 deficiency in patients of type 2 diabetes mellitus on metformin: a case control study from Pakistan. The Pan African Medical Journal 2013; 16: 67.

11. Green S, Watson R. Nutritional screening and Assessment Tools for older adults: Literature Review. Journal of Advance nursing. 
2006;54(4):477-90.

12. McElnay C, Marshall B, O'Sullivan J, Jones L, Ashworth T, Hicks K, Forrest R. Nutritional risk amongst community-living Maori and nonMaori older people in Hawke's Bay. Journal of primary health care. 2012;4(4):299-305.

13. Graham GG, Punt J, Arora, M, Day RO, Doogue, MP, Duong JK, Williams KM. Clinical Pharmacokinetics of metformin. Clinical Pharmacokinetics. 2011;50(2):81-98.

14. Herrmann W and Obeid R. Holotranscobalamin - An Early Marker for Laboratory Diagnosis of Vitamin B12 Deficiency. EurOncolHaematol 2009;03:7.

15. Monsen AL, RefsumH, Markestad T and Ueland PM. Cobalamin Status and Its Biochemical Markers Methylmalonic Acid and
Homocysteine in Different Age Groups from 4 Days to 19 Years. ClinChem 2003;49: 2067-2075.

16. Setola E, Monti LD, Gallucio E, Palloshi A, Fragasso G, Paroni R, et al. Insulin resistance and endothelial function are improved after folate and vitamin B12 therapy in patients with metabolic syndrome: relationship between homocysteine levels and hyperinsulinemia. Eur J Endocrinol 2004; 151: 483-489.

17. Bonora E, Kiechl S, Mayr A, Zoppini G, Targher G, Bonadonna R, et al. High-Normal HbA1c Is a Strong Predictor of Type 2 Diabetes in the General Population. Diabetes Care 2001;34: 1038-1040.

Copyright: () the author(s), 2019. It is an open-access article distributed under the terms of the Creative Commons Attribution License (CC BY 4.0), which permits authors to retain ownership of the copyright for their content, and allow anyone to download, reuse, reprint, modify, distribute and/or copy the content as long as the original authors and source are cited.

How to cite this article: Jampana KR, Paka AC. Vitamin B12 Status in Type 2 Diabetes Mellitus Patients on Metformin therapy: A Teaching Hospital Based Study. Asian J. Med. Res. 2019;8(1):ME06-ME09.

DOI: dx.doi.org/10.21276/ajmr.2019.8.1.ME3

Source of Support: Nil, Conflict of Interest: None declared. 